\title{
A Phase-Based Account of Wh-Questions in Standard Arabic
}

\author{
Mohammad O. Al-Shorafat \\ English Department, Yarmouk University, Irbid,63-211,Jordan \\ *Corresponding Author: mshorafat@yu.edu.jo
}

Copyright @ 2013 Horizon Research Publishing All rights reserved.

\begin{abstract}
The main concern of this paper is to investigate the syntax of Wh-questions in Standard Arabic (SA). This investigation will be conducted within the latest framework envisaged by Chomsky (1998, 1999, 2001, 2005, and 2006). Chomsky's latest version has been termed a phase-based theory of syntax. As far as I know SA Wh-questions have not been analyzed within this framework. I think it is worth the trouble knowing if recent developments in the syntactic theory are applicable to a non-Indo-European language such as SA. As is well known there is scarcity of studies on SA in this modern line of research. If SA along with other languages can be handled within the phase-based theory of syntax, this will provide a cross-linguistic evidence for the universality of this theory; if not, further research needs to be conducted before reaching any definitive conclusions.
\end{abstract}

Keywords SA, Phase, Wh-questions, Minimalist Syntax, CP, vP

\section{Introduction}

Since the seminal work of Chomsky (1977) on Wh-questions in English, there have been a large number of studies on Wh-questions in different languages. To cite just a few, Cole and Herman (1998) study the typology of wh-movement in Malay. They investigate the principles which govern overt wh-movement as well as wh-in-situ and partial wh-movement within an earlier version of the minimalist framework (Chomsky,1995). Grewendorf (2001) argues that overt multiple wh-movement in Bulgarian consists of moving a wh-cluster to spec-CP. He also maintains that wh-movement is due to morphological properties of wh-words. Boškovič (2002) demonstrates that multiple wh-fronting languages do not behave in a similar fashion with regard to wh-movement; thus he crosses them out from the cross-linguistic typology he endeavours to establish. Citko (2006) studies the relationships between two independent wh-movement strategies: across the board wh-movement and left branch extraction in Slavic languages. He claims that both strategies are possible, independent of each other, but putting them together is determined by a number of constraints. Khomitsevich (2009) studies long-distance wh-movement in Russian. She shows that while extraction out of indicative complement clauses is ungrammatical, extraction out of subjunctive complement clauses is grammatical. She states that problems of long-distance wh-movement in Russian is due to the fact that, unlike English, $\mathrm{T}$ and not $\mathrm{C}$ is the phase head in Russian and she offers a number of arguments to support her proposals.

Modern Arabic linguists have also discussed the syntax of wh-questions in Arabic. Aoun and Benmamoun (1998) conduct a study on the interaction among clitic left-dislocation, wh-interrogatives and topicalization in Lebanese Arabic. Nouhi (1996) also investigates wh-questions in Moroccan Arabic. He concentrates on different types of constructions, such as relative clauses, topicalization, and wh-questions. What's interesting about his analysis is his claim that phrases are attached to a topic phrase which is dominated by a CP and the Topic phrase dominates an IP.

I have cited the previous wh-constructions studies as background information. However, I haven't gone into them in any detail. Their importance stems from the fact that they are conducted on different languages, and dialects within different theoretical frameworks. For more on these studies, I refer the interested reader to the reference section in this paper.

\section{Phase-Based Framework}

Before presenting and investigating SA wh-constructions, I believe it is only appropriate to review the main aspects of 
Chomsky's $(1999,2001,2005,2006)$ phase-based syntactic model. In a phase-based model, a clause has the following standard structure:

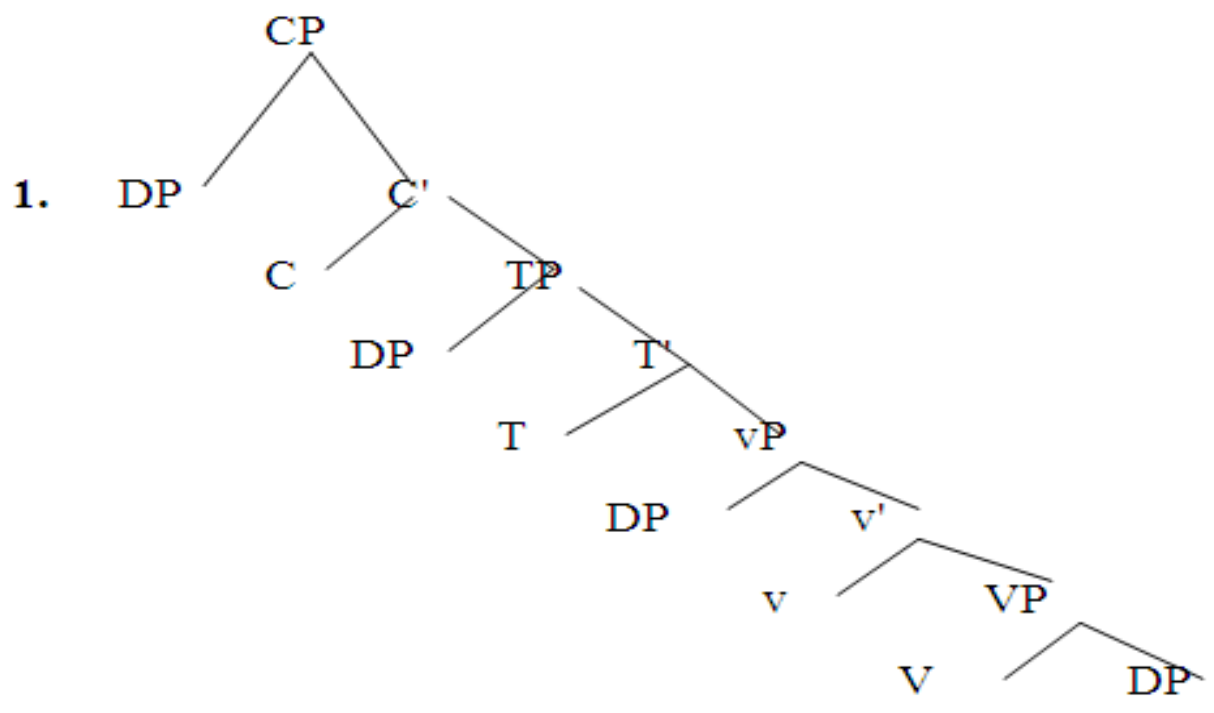

From the tree structure above, it can be seen that we have an inner VP and an outer vP shell. It can also be noticed that even root clauses are introduced by CPs in order to show if the clause has a declarative, interrogative, imperative or exclamative force. Introducing root clauses with a $\mathrm{CP}$ specifier and a $\mathrm{C}$ head has not been standard practice in previous studies in the linguistic literature. Chomsky $(1999,9)$ considers CP and transitive vP (which he denotes as $\mathrm{v}^{*} \mathrm{P}$ ) as propositional phases. His reason for taking $\mathrm{CP}$ and $\mathrm{v}^{*} \mathrm{P}$ as phases is that $\mathrm{CP}$ represents a complete complex including its force marker (indicative, interrogative...etc.), and $\mathrm{vP}$ represents a complete thematic complex with an external argument. He also maintains that $\mathrm{C}$ and $\mathrm{v}$ are phase heads and that syntactic operations involve an agreement relation between a probe $\mathrm{P}$ and a local goal $\mathrm{G}$ (Chomsky1998, 1999, 2001). He further posits that $\mathrm{C}^{1}, \mathrm{~T}$ and $\mathrm{v}$ are probes and that merger operations apply before any probing can take place. He also proposes that a TP which is contained within a CP as in (1) above is a complete clause while infinitival embedded clauses which lack CPs are considered defective TP clauses. He further adds that defective TPs and vPs that lack an external thematic argument are not phases. He adds that probes can probe either simultaneously or sequentially with some choices converging while others crashing (Chomsky 2006, 17). When all syntactic operations in a given phase have been completed, the complement of the phase head becomes impenetrable to further syntactic operations which Chomsky (2001) terms the Phase Impenetrability Condition. The reason why the complement or (the domain) of the phase becomes impenetrable, according to him, is because this domain undergoes transfer simultaneously to the phonological component and the semantic component to be assigned the appropriate representations.

\section{Wh-Constructions in SA}

Before presenting any wh-constructions in SA, I'll adopt the clause structure in (1) as the clause structure in SA. I'll also adopt the dominant word order in SA, viz, VSO. I'll assume that T in SA doesn't project a specifier phrase because it lacks an EPP feature. The reason for this assumption is that the subject does not move from its spec-vP position, it remains in situ or if there is movement we'll get an SVO order which is a different word order from VSO. The T head is an abstract, affixal element which has either a past or present tense. Further, it is a well-known fact in SA that in the VSO order, there is lack of agreement (in person and number) between the $\mathrm{V}$ and the subject, so in a sense we have default agreement. ${ }^{2}$ However, the head $\mathrm{T}$ in finite clauses probes for a local (pro)nominal goal to assign nominative case to it.

\subsection{Intransitive Structures in SA}

\footnotetext{
${ }^{1}$ It should be mentioned at this point that Chomsky (1999, $\left.35 \mathrm{fn} 17\right)$ suggests that "The focus of nominative case and subject-verb agreement is C, not T." Chomsky (2006) also argues theoretically in support of his claim that agreement features originate on phase heads $(\mathrm{C}, \mathrm{v})$ and then percolate down onto the heads beneath them $(\mathrm{T}, \mathrm{V})$. For counter arguments to Chomsky's position on feature inheritance, I refer the reader to Redford (2009, $403 \mathrm{ff})$ and to the syntactic behavior of the complementizer? anna in this paper.

${ }_{2}^{2}$ It should be pointed out that in VSO order there is only gender agreement between the subject and the verb. In sentence (4), there is gender agreement between the verb and the subject.
} 
Let's start with intransitive structures in SA.

2. a. Mataa r-rajul-u.

Died the man-Nom

b. Mataa man

Died who

c- Mann mataa?

"Who died?"

3. a- Namaa 1-walad-u.

Slept the-boy-Nom

b- Namaa man

Slept who

c. Mann namaa ?

"Who slept?"

4. a. Mata-t 1-bint-u.

Died-fem the girl-Nom

b. Mata-t man

Died who

c. Mann mata- $\mathrm{t}^{3}$ ?

Who died

"Who died ?"

5. a. Yargusu r-rajal-u

Dance the man-Nom

b. Yargusu mann

Dance who

c. Mann yargusu ?

"Who dances?"

${ }^{3}$ It is important to note that while (4c) which shows gender agreement is acceptable, we can have (i) mann mataa? without gender agreement.

The previous intransitive examples show that there is wh-movement to the left periphery of the clause. It is also clear that once we replace the subject with the question word mann, the nominative case becomes invisible. Using the standard clause structure in (1), let's see how sentence (2) is derived. 


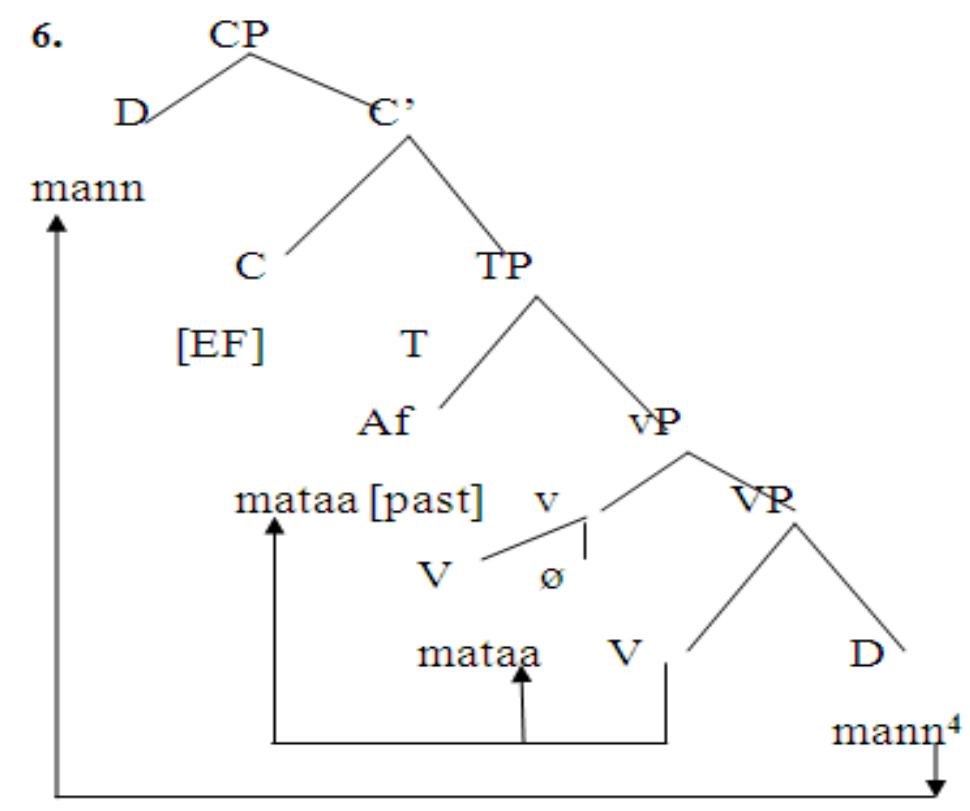

${ }^{4}$ It should be stressed that lower copies of moved elements like mann and mataa in (c) above and all tree diagrams and bracketing in this paper receive a null spellout; the only copy that is visible in the PF component is the highest one.

The derivation in (6) proceeds as follows. The V mataa merges with the D man to form the VP. The VP in turn merges with the light affixal $\mathrm{v}$ which triggers movement of the $\mathrm{V}$ mataa to adjoin to it, forming the $\mathrm{vP}$; we notice here that the $\mathrm{vP}$ has no specifier because the clause is intransitive which means that $\mathrm{v}$ lacks an external thematic argument. It is also important to mention here that $\mathrm{vP}$ is not a phase and $\mathrm{v}$ is not a phase head; hence, it is not a probe. Since $\mathrm{vP}$ is not a phase; its domain (the VP) is not transferred and the syntactic computation continues. The vP merges with an abstract past tense Af. T agrees with and assigns invisible nominative case to man. TP merges with a null interrogative $\mathrm{C}$ which bears an edge feature (EF) which triggers movement of the question word mann to the specifier of CP. After movement of mann to spec-CP, the EF deletes. Since $\mathrm{T}$ is strong and affixal, it triggers movement of the complex $\mathrm{V}+\mathrm{v}$ to adjoin to it. Now $\mathrm{CP}$ is a phase; its domain the TP undergoes transfer to the PF and LF components to receive its appropriate representations and the lower copies of the moved constituents will receive a null spellout in the phonological component. $\mathrm{T}$ and the complex verb will surface as past. At the end of the derivation, the remaining constituents mann and $\mathrm{C}$ are transferred and the clause is interpreted as interrogative. It should be noted that the movement of the wh-expression, mann is an A-bar movement since mann moves into a spec-CP which is a non-argument position. The derivation in (6) has shown that Chomsky's $(1999,2001,2005,2006)$ phase theory of syntax provides a principled account to the derivation of intransitive structures in SA. However, let's see how we could derive a wh-expression from a transitive clause.

\subsection{Transitive Structures in SA}

Consider the following examples.

7. a. Kataba r-rajul-u risaalt-an.
Wrote the man-Nom letter-Acc
b. Kataba r-rajul-u madaa.
Wrote the-man-Nom what
c. Maðaa kataba r-rajul-u ?
What wrote the-man-Nom
"What wrote the man?"


8. a. Ya?kulu 1-walad-u xubz-an.

Eat the-boy-Nom bread-Acc

b. Ya?kulu man xubz-an

Eat who bread-Acc

c. Mann ya'kulu xubz-an?

"Who eat(s) bread?"

Let's see how the wh-expression maðaa in (7) can be derived if we use the clause structure in (1).

9.

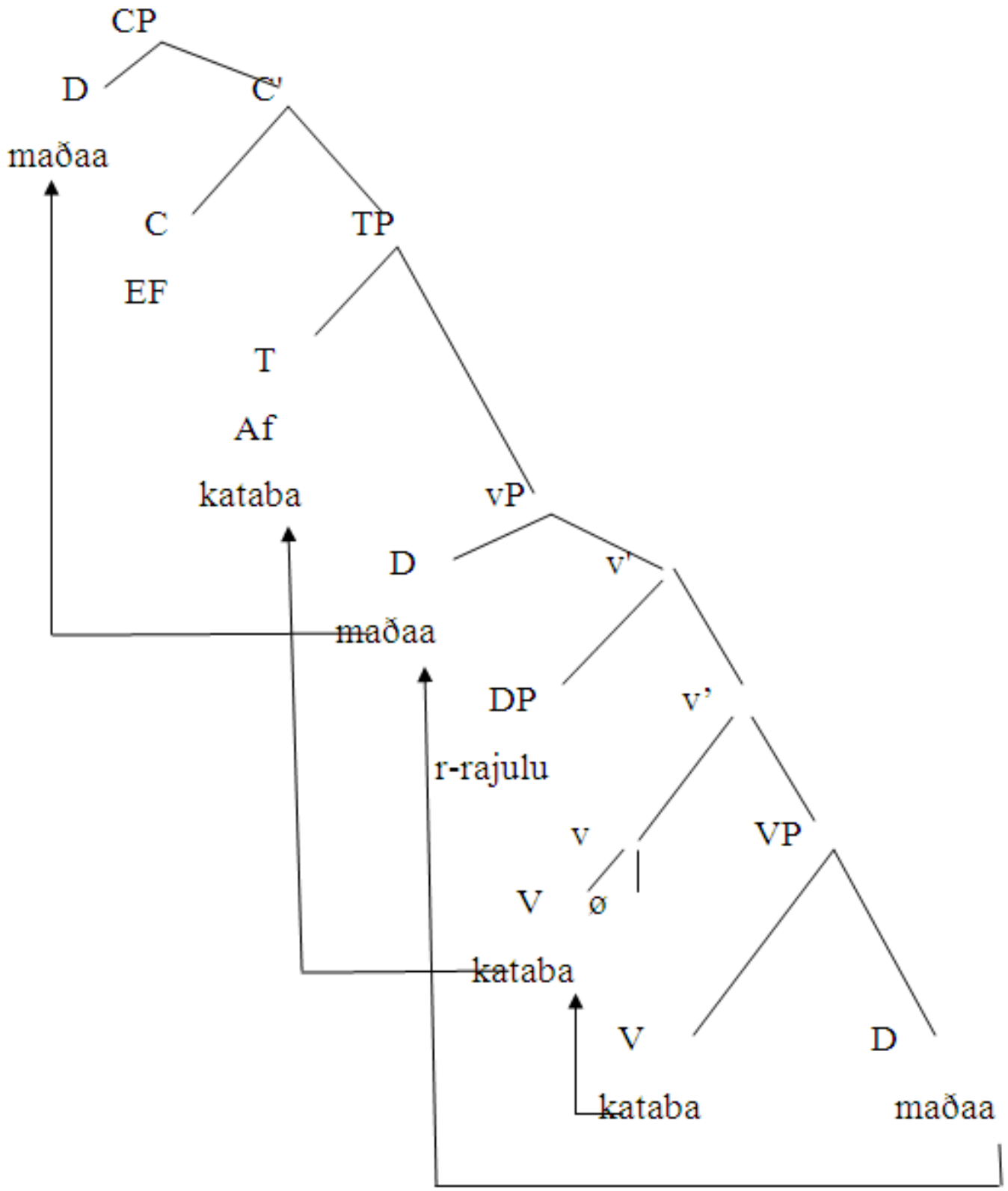

The derivation in (9) proceeds in the following manner. The V kataba merges with the question word maðaa to form the VP. The VP in turn merges with a light affixal $\mathrm{v}$ which triggers the movement of the $\mathrm{V}$ kataba to adjoin to it. Now $\mathrm{v}$ merges 
with the specifier $r$-rajulu to form a $\mathrm{v}^{\prime}$ which is a split category. Now $\mathrm{v}$ is a phase head because it has an external thematic argument $r$-rajulu; hence, $\mathrm{v}$ is a probe. $\mathrm{v}$ probes for a local goal and finds maðaa; $\mathrm{v}$ agrees with and assigns accusative case to $m a ð a a$. In Chomsky's model, it is assumed that just as $\mathrm{C}$ can have an edge feature which attracts a wh-expression, the light transitive $\mathrm{v}$ (by virtue of being a phasal head like C), can have an edge feature attracting maðaa to become the second (outer) specifier of vP as in (9) above. This means that a head can have multiple specifiers (Chomsky, 1998, 16). Now vP is a phase; its complement the VP will undergo transfer, the null copies of the moved constituents will be given a null spellout. The derivation continues by merging $\mathrm{vP}$ with $\mathrm{T}$ forming a TP. T is a probe, it searches for a goal within its c-commanding domain; there are two possible goals maðaa and $r$-rajulu. However, according to Chomsky once the case of a goal has been valued and deleted as is the case with maðaa, the goal becomes inactive for agreement with or attraction by a head like T. Of course not to forget that T in SA doesn't have an EPP feature to trigger movement. However, maðaa intervenes between T and $r$-rajulu. At this point, we can follow Boeckx $(2007,83)$ in assuming that a D like maðaa with an already valued case feature becomes transparent for T, i.e., T can see through maðaa and locates $r$-rajulu as the closest active goal. $\mathrm{T}$ agrees with and assigns nominative case to the DP $r$-rajul-u. However, $r$-rajulu remains in situ since T in SA lacks an EPP feature. Since $\mathrm{T}$ is strong and affixal, it attracts the movement of the complex $\mathrm{V}+\mathrm{v}$ to check the tense feature and provide a host for it. ${ }^{5} \mathrm{TP}$ is not a phase, so the derivation proceeds by merging $\mathrm{TP}$ with a null interrogative $\mathrm{C}$ which carries an $\mathrm{EF}$ which attracts the movement of maðaa from the edge of $\mathrm{vP}$ to the specifier of CP. CP is a phase and its TP complement is sent simultaneously to the PF and the LF components, after that the head C and its specifier maðaa are sent to the PF and LF components and the clause is interpreted as interrogative.

Let's see what happens if we question the subject in (8) above. The derivation of the clause in (8) is as follows

10.

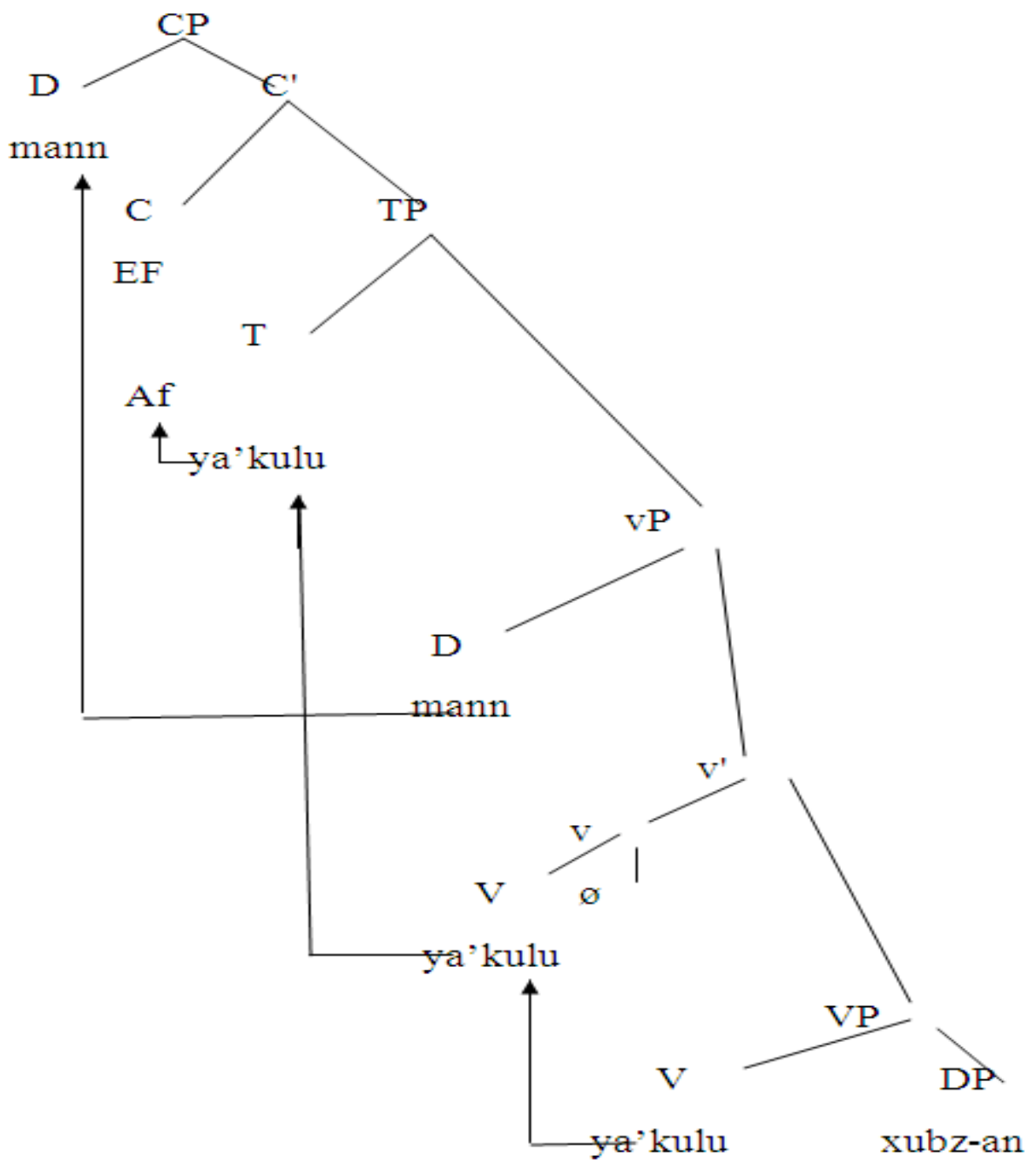

In (10) above, ya?kulu merges with $x u b z$-an to form the VP. The VP in turn merges with a light affixal $\mathrm{v}$ forming a $\mathrm{v}^{\prime}$. The

\footnotetext{
${ }^{3}$ It should be stressed here that since $\mathrm{V}$ has been moved to adjoin to the head of vP, the V is no longer within the VP domain, but its copy is.
} 
$\mathrm{v}$ triggers movement of the verb ya?kulu to adjoin to it. The $\mathrm{v}^{\prime}$ merges with the specifier mann to form a vP. Since $\mathrm{v}$ has an external argument then $\mathrm{vP}$ is a phase. The $\mathrm{v}$, the head of the phase probes for a local (pro)nominal goal. It locates $x u b z$ with which it agrees and assigns accusative case. The VP, the domain of the vP phase undergoes transfer to the PF and LF components. The lower copy of the $\mathrm{V}$ receives a null spellout in the PF component. The VP is no longer accessible to any syntactic operations or probing from outside the vP. However, the syntactic computation continues by merging vP with $\mathrm{T}$ forming a TP which in turn merges with a null $\mathrm{C}$ head to form a $\mathrm{C}^{\prime}$ and since $\mathrm{C}$ has an $\mathrm{EF}$, it projects into a $\mathrm{CP}$. The $\mathrm{T}$ is a probe; it searches for a goal and the only available goal is mann with which it agrees and assigns invisible nominative case, but doesn't trigger movement because as said before T lacks an EPP feature. Now C is a probe; it has an EF which triggers mann movement to specifier CP. CP is a phase; TP is its complement. TP is sent to the PF and LF components. At the end of the derivation, the specifier mann and the head $\mathrm{C}$ are sent to the phonological and semantic components and the sentence is interpreted as an interrogative and we get the grammatical sentence in (8c). At this point, we can conclude that wh-questions in intransitive and transitive SA clauses can be moved to the left periphery of the clause and that extraction is admissible from object as well as subject positions. It is also important to note that up to this point, Chomsky's phase-based theory applies in a principled fashion to the SA clause structures considered so far. What about multiple wh-questions in SA?

\subsection{Multiple Wh-questions in SA}

A salient property of multiple wh-questions in SA is that only one wh-expression can move to the left periphery of the clause as is the case in other languages such as English. Let's consider the following examples.

11. Mann kataba maðaa?
"Who wrote whote what?"
12. "Maðaa kataba mann?
"What wrote who
"Mann maðaa whote who?"
Who what
"*Who what wrote?"
*Maðaa mann kataba
What who wrote
"*What who wrote?"

It can be clearly observed from the above examples, that in SA multiple wh-expressions only one wh-question can be fronted and in a transitive clause as in the above examples, only the subject can move, not the object as is clear in (11) and (12). However, fronting more than one wh-question in either word order is not admissible as the ungrammaticality of (13) and (14) show. In order to show why we can't front more than one wh-expression and why the preposed item has to be mann and not maðaa, let's draw the following tree diagram: 
15.

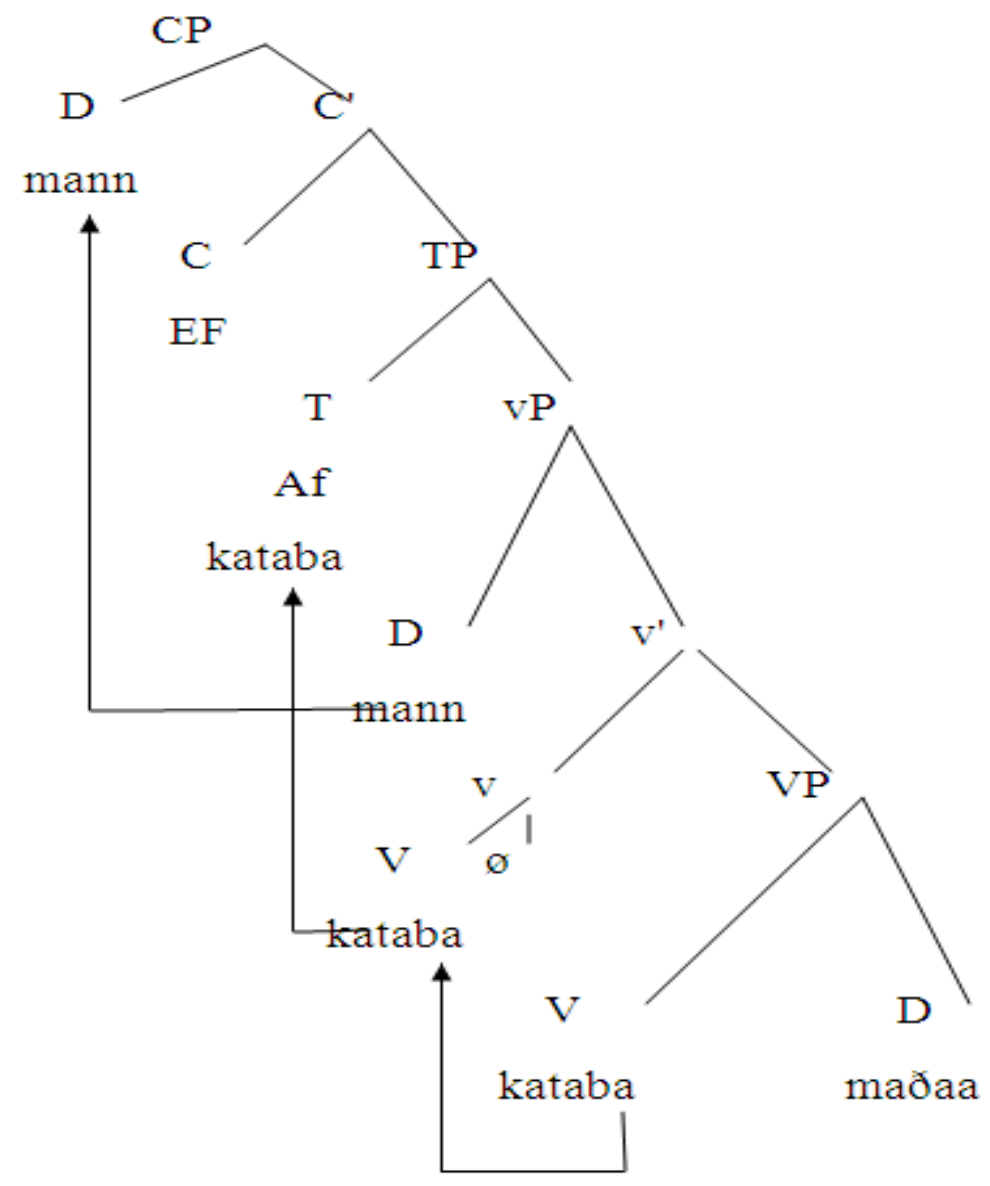

The derivation in (15) proceeds as follows. kataba merges with maðaa to form the VP kataba maðaa. The VP merges with a light affixal $\mathrm{v}$ forming a $\mathrm{v}^{\prime}$. The light $\mathrm{v}$ triggers movement of the $\mathrm{V}$ to adjoin to it. The $\mathrm{v}^{\prime}$ merges with an external agent mann forming a $\mathrm{Vp} ; \mathrm{vP}$ is a phase. The $\mathrm{v}$ agrees with and assigns accusative case to the complement maðaa. However, at this point neither T nor C can probe into the vP phase domain because of Chomsky's (2001) Phase Impenetrability Condition which roughly states that the domain of a phase head in our case the VP is impenetrable to any external probe $(\mathrm{C}$ or $\mathrm{T})$ c-commanding the phase. Hence, the vP domain is no longer accessible to the syntax. Since $\mathrm{C}$ and $\mathrm{T}$ are in the same phase, CP; they will search for a local goal and the only local goal available is mann, at the edge of the vP phase. T will assign an invisible nominative case to mann and $\mathrm{C}$ will trigger its movement to spec-C in order to satisfy the EF on C. At this stage, the TP domain will be sent to the phonological and semantic components to get the appropriate representation in each component. Subsequently, the constituents at the edge of CP will undergo transfer as well. Now, we are in a position to explain why $m a ð a a$ can't be fronted either alone as in (12) or together with man as in (13) and (14). At the computation stage when the vP merges with $\mathrm{T}$ to form TP and TP merges with $\mathrm{C}$ to form $\mathrm{C}^{\prime}$, since its case has been assigned, maðaa is no longer present in the derivation because the VP has undergone transfer to the appropriate levels. This fully explains the ungrammaticality of (12), (13) and (14) above. At this point, we move to consider extraction of wh-expressions from complement clauses.

\subsection{Embedded Wh-questions in SA}

Traditionally, embedded Arabic clauses have been classified into verbal and nominal complements. Nominal complements are introduced by the complementizer ? anna immediately followed by a nominal. Verbal complements are introduced by the complementizer? an immediately followed by a verb (Abedul Ghani, 1981, 6). Let's consider the following examples.

$$
\begin{aligned}
& \text { 16. Oanunt-u ?anna zayd-an qara'a 1-maqaalat-a. } \\
& \text { Though I that Zayd-Acc read the-essay-Acc }
\end{aligned}
$$

"I thought that Zayd read the article". 


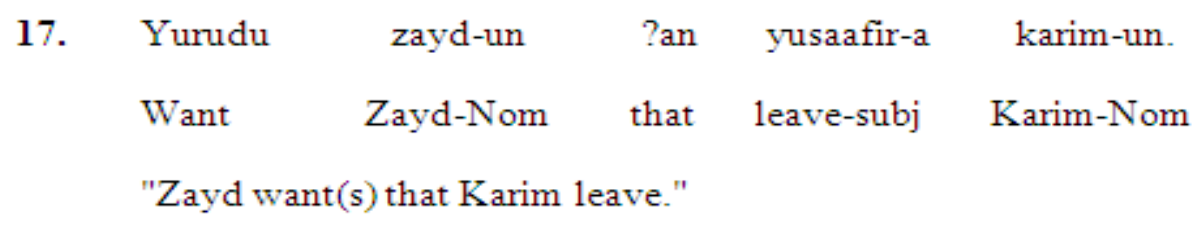

It is a well-known fact of Arabic syntax that the complementizer ?anna must be followed by a (pro)nominal in the accusative and the verb in the embedded clause is indicative whether perfect or imperfect as in (16) above. It is also a well-known fact of Arabic syntax that the complementizer ?an must be followed by a verb in the subjunctive if it is imperfect and the (pro)nominal is nominative as in (17) above. ${ }^{4}$ Let's start with wh-extraction out of object position of a verbal complement in SA. Consider the following example.

18. Yurudu zayd-un ?an ya'ktub-a karim-un risaalat-an.
Want Zayd-Nom that write-Subj Karim-Nom letter-Acc
"Zayd want(s) that Karim write a letter."

Using a skeletal bracketing and not showing all the details involved, but concentrating on the movement of risaalat-an= $m a ð a a=$ what, we'll have the following.

19.

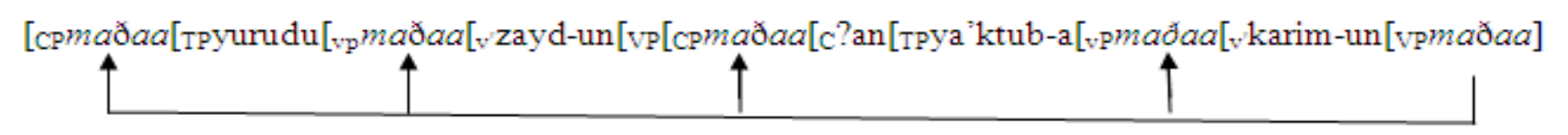

The verb ya?ktub merges with maðaa to form the VP. The VP merges with the light $\mathrm{v}$ to form a $\mathrm{v}$. The $\mathrm{v}$ triggers the V ya?ktub to move and adjoin to it. The $v^{\prime}$ merges with the external argument Karim and maðaa moves to occupy the outer specifier of vP to satisfy the EF of the phase head v; the verb ya?ktub moves to the T of the TP where it receives the subjunctive feature from the complementizer ?an; maðaa moves to the spec-CP in the complement clause to satisfy the EF of the complementizer ?an, since the $\mathrm{vP}$ in the matrix clause is a phase, the wh-expression maðaa moves to the outer specifier of the vP. From there it moves to the spec-position of the matrix clause as the arrows indicate in (19) above. It can be clearly seen that the movement of maðaa from its original position is successive-cyclic. It should also be mentioned that whenever the syntactic operations in every phase are completed, the domain of each phase is sent to the phonological and semantic components to be given the appropriate representation. We should also indicate that the lower copies of the moved constituents receive a null spellout in the phonological component. Let's see what happens when we extract a wh-word from a subject position in a verbal complement clause. We'll take the same example in (18) repeated here as (20) and replacing the subject with mann.

20. Yurudu zayd-un ?an ya'ktub-a mann risaalat-an.
Want Zayd-Nom that Write-subj who letter-Acc

\footnotetext{
${ }^{4}$ It should be mentioned that the complementizer ?an has a lighter form ?an which requires an indicative verb followed or preceded by a nominative nominal. However, extraction from the complement of the light ?an is identical to the extraction in (19) and (21); hence, there is no need to present more examples of this light form.
} 
"Zayd want(s) that write who a letter."

21. Mann yurudu zayd-un ?an ya'ktub-a risaalat-an?
Who want $\quad$ Zayd-Nom that write-Subj letter-Acc

"Who want(s) Zayd that write a letter?"

Using a skeletal bracketing and concentrating on the movement of mann and ignoring all other details of the syntactic operations we'll have the following.

22.

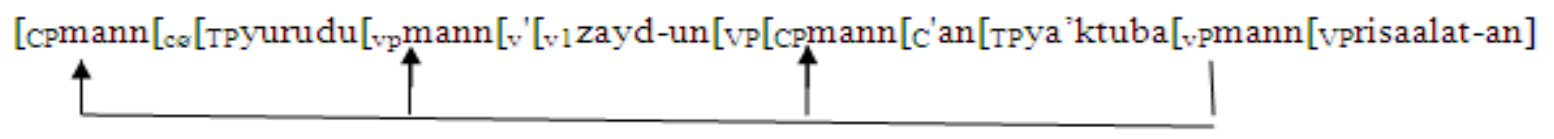

As is clear from (22) mann is located in the spec-position of the embedded vP phase. As indicated by the arrows, it moves first into the spec-CP of the embedded verbal complement clause. Next, it moves from spec-CP into the outer specifier position of the $\mathrm{VP}$ phase in the matrix clause; then it moves into the spec-CP of the matrix clause. The movement is successive cyclic and is driven by an EF at the edge of every phase. We can conclude at this point that extraction of wh-expressions out from object and subject positions from verbal complement clauses in SA is admissible. It should be mentioned that contrary to English which does not allow wh-extraction out from subject position in embedded clauses; SA does allow such extraction. Now, we want to check wh-extraction out of a nominal complement in SA. But before going into any concrete examples, let's lay out certain necessary assumptions at this stage. First, I will assume following Abedul Ghani (1981) that the nominal following the complentizer? anna is a topic. Second, I'll

also assume following Rizzi $(1997)^{5}$ that there is a split CP in nominal complements in SA. Rizzi suggests that CP must be split into a number of different projections. His suggestion has come to be known as the split CP hypothesis. Rizzi argues that in addition to the highest force phrase (CP) which determines if the sentence is indicative, interrogative, imperative... etc.,there are other phrases such as Focus Phrase, Topic Phrase, Finiteness Phrase... etc. In our case there is a separate topic phrase immediately beneath the force phrase. However, with respect to the topic, there is a difference between English and SA. While in English a topic phrase is the result of a topicalization process which involves movement; in SA, a topic is base-generated. To see how a split CP is represented in a nominal complement in SA, let's consider the following example.

23. đanna zayd-un ?anna karim-an qara'a 1-maqaalat-a.

Thought Zayd-Nom that Karim-Acc read- the-essay-Acc

"Zayd thought that Karim read the essay."

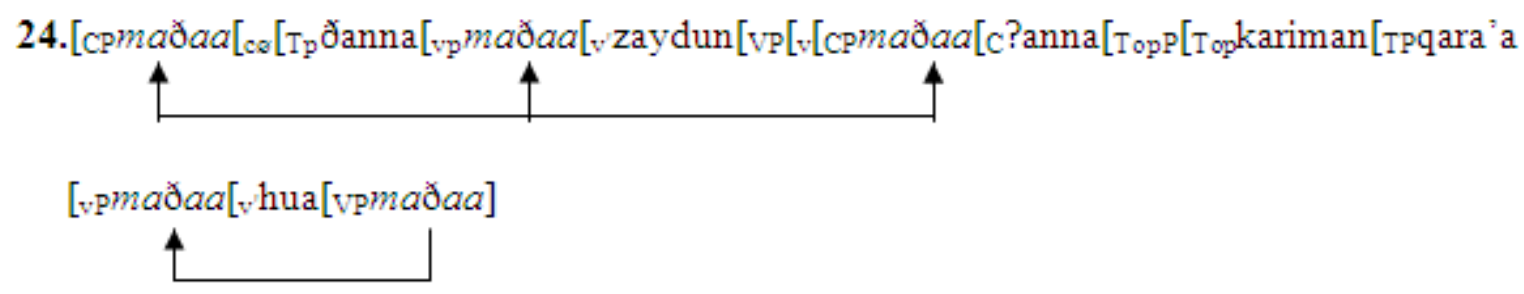

It can be seen from (24) above that the CP of the nominal complement has been split into two CPs: the force CP with its

\footnotetext{
${ }^{5}$ It should be pointed out that Rizzi's split CP hypothesis is posited for English.
} 
complementizer ?anna which indicates that the clause is indicative and the TopicP which has the Topic Karim-an. ${ }^{6}$ The derivation in (24) proceeds as follows. The verb qara'a merges with maðaa to form the VP. The VP merges with a light $v$ to form a v'. The $v$ triggers the movement of the $\mathrm{V}$ qara'a to adjoin to it. Since $\mathrm{v}$ is a phase head, it'll agree with and assign accusative case to maðaa. The v' merges with an invisible external pro"hua" (he) which refers back to the topic Karim-an. At this point maðaa moves to the outer specifier position of the phase vP. The vP merges with a T to form a TP; the TP merges with the Topic to form a topic phrase. The topic phrase merges with ?anna to form a CP. qara'a moves and adjoins to the strong tense affix and maðaa moves to the specifier of ?anna because ?anna has an EF that has to be satisfied and deleted. The vP merges with T to form a TP; the TP merges with the Topic to form a topic phrase. The topic phrase merges with ?anna to form a CP. The CP merges with the verb ðanna to form the VP; the VP merges with a light verb triggering the movement of the verb ðanna to adjoin to it and form a v'; the $\mathrm{v}^{\prime}$ merges with the DP Zaydun and maðaa moves to the outer specifier of vP. $\mathrm{T}$ probes for a goal, the only available goal is Zayd with which it agrees and assigns nominative case (we have already mentioned that the case feature of maðaa had already been valued and deleted in the LF component, but it is visible in the PF component. Then maðaa moves to the outer specifier of the $\mathrm{vP}$ phase in the matrix clause. The verb ðanna $+\mathrm{v}$ moves and adjoins to T. maðaa moves out of spec-vP and ends up in the specifier position of the matrix CP. The lower copies of the moved constituents receive a null spellout. As can be seen the movement is successive cyclic and the result is a grammatical question.

Let's see what happens if we extract from a topic position. Consider the following example.

$$
\text { 25. *Mann Janna zayd-un qara'a 1-maqaalat-a? }
$$

$$
\text { Who thought Zayd-Nom that read-hua the-essay-Acc }
$$

\section{"*Who thought Zayd that read the essay?"}

This sentence is ill-formed. We have to explain the ill-formedness of this sentence. If we go back to sentence (24) we'll observe that the closest goal to the probe ?anna is the topic Karim with which it agrees and assigns accusative case. In Chomsky's recent phase theory, once the case feature of a goal, in our case, the topic, has been valued and deleted, the goal becomes inactive for agreement with or attraction by another probe. In other words, after ?anna assigns accusative case to the topic Karim; Karim-an is frozen in place, i.e., it can't be moved or attracted into another position and this readily explains the ungrammaticality of sentence (25).

\section{Conclusion}

In this paper I have investigated the syntax of wh-questions in SA, I have conducted this investigation within Chomsky's latest framework which has been termed a phase-based theory of syntax. I have shown that wh-questions in SA, a non-Indo European language can be accounted for in a principled fashion within this phase-based theory. I have also shown that agreement and movement do obey the principles of the phase theory and that this theory not only accounts for well-formed sentences but ill-formed sentences as well. The applicability of this theory to the wh-structures of SA provides strong evidence to the universality of this theory and paves the way for recent treatments of SA constructions. However, this paper left open for future research the syntactic behavior of yes-no questions and wh-questions in a SVO order.

\section{REFERENCES}

[1] Abedul Ghani, K. 1981. Government Binding in classical Arabic. Ph.D. Dissertation. University of Texas at Austin.

[2] Aoun, J. and Benmamoun, E. 1998. Minimality. Reconstruction, and PF Movement. Linguistic Inquiry 29, $569-597$.

[3] Boeckx, C. 2007. Understanding Minimalist Syntax. Oxford. Blackwell.

\footnotetext{
${ }^{6}{ }^{8}$ It should be pointed out that topics in root clauses have a nominative case. However, here it can be seen that the nominative case is overridden by the accusative case assigned by the complementizer? anna. Another alternative is to posit that the topic Karim enters the derivation with an unvalued case in this particular example; once it merges with ?anna, it receives its accusative case.
} 
[4] Bošković, Z. 2002. On Multiple Wh-Fronting. Linguistic Inquiry 33, 35-381.

[5] Chomsky, N. 1977. On Wh-Movement. In Culicover, P.T. Wason and A. Akmajian, eds. Formal Syntax. New York: Academic Press.

[6] Chomsky, N. 1995. The Minimalist Program. MA., Cambridge, MIT Press.

[7] Chomsky, N.1998. Minimalist Inquiries: The Framework. MIT Occasional Papers in Linguistics, 15.

[8] Chomsky, N. 1999. Derivation by Phase : MIT Occasional Papers in Linguistics, 18.

[9] Chomsky, N.2001. Beyond Explanatory Adequacy.Unpublished Manuscript, MIT.

[10] Chomsky, N. 2005. On Phases. Unpublished Paper, MIT.

[11] Chomsky, N.2006. Approaching UG from Below. Unpublished Paper. MIT.

[12] Citko, B. 2006. The Interaction Between Across-the-Board Wh-movement and Left Branch Extraction. Syntax 9, 3, $225-247$.

[13] Cole, P. and G. Herman. 1998. The Typology of Wh-Movement, Wh-questions in Malay. Syntax 1, 3, 221-258.

[14] Grewendorf, G. 2001. Multiple Wh-Fronting. Linguistic Inquiry 32, 87-122.

[15] Khomitsevich, O. 2007. Dependencies Across Phases: From Sequence of Tense to Restrictions on Movement. Published Ph.D. Dissertation. The Netherlands: Lot.

[16] Nouhi, Y. 1996. Wh-Constructions in Moroccan Arabic. MA Thesis, University of Ottawa, Canada.

[17] Rizzi, L.1997.The Fine Structure of Left Periphery.In Haegeman,L.,ed.Elements of Grammer. Dordrecht, Kluwer. 